\title{
Novel Biomarkers of Alzheimer's Disease: Based Upon N-methyl- D-aspartate Receptor Hypoactivation and Oxidative Stress
}

\author{
Ting-I Chiang ${ }^{1}$, Yi-Hsiang $\mathrm{Yu}^{2}$, Chieh-Hsin Lin ${ }^{1,3,4}$, Hsien-Yuan Lane ${ }^{4,5,6}$ \\ Departments of ${ }^{1}$ Psychiatry and ${ }^{2}$ Dermatology, Kaohsiung Chang Gung Memorial Hospital, Chang Gung University College of Medicine, \\ Kaohsiung, ${ }^{3}$ School of Medicine, Chang Gung University, Taoyuan, ${ }^{4}$ Graduate Institute of Biomedical Sciences, China Medical University, \\ ${ }^{5}$ Department of Psychiatry and Brain Disease Research Center, China Medical University Hospital, ${ }^{6}$ Department of Psychology, College of \\ Medical and Health Science, Asia University, Taichung, Taiwan
}

\begin{abstract}
Early detection and prevention of Alzheimer's disease (AD) is important. The current treatment for early AD is acetylcholine esterase inhibitors (AChEls); however, the efficacy is poor. Besides, AChEI did not show efficacy in mild cognitive impairment $(\mathrm{MCl})$. Beta-amyloid $(\mathrm{A} \beta)$ deposits have been regarded to be highly related to the pathogenesis of $\mathrm{AD}$. However, many clinical trials aiming at the clearance of $A \beta$ deposits failed to improve the cognitive decline of $A D$, even at its early phase. There should be other important mechanisms unproven in the course of $\mathrm{AD}$ and $\mathrm{MCl}$. Feasible biomarkers for the diagnosis and treatment response of $\mathrm{AD}$ are lacking to date. The $\mathrm{N}$-methyl-D-aspartate receptor (NMDAR) activation plays an important role in learning and memory. On the other hand, oxidative stress has been regarded to contribute to aging with the assumption that free radicals damage cell constituents and connective tissues. Our recent study found that an NMDAR enhancer, sodium benzoate (the pivotal inhibitor of D-amino acid oxidase [DAAO]), improved the cognitive and global function of patients with early-phase AD. Further, we found that peripheral DAAO levels were higher in patients with $\mathrm{MCl}$ and $\mathrm{AD}$ than healthy controls. We also found that sodium benzoate was able to change the activity of antioxidant. These pieces of evidence suggest that the NMDAR function is associated with anti-oxidation, and have potential to be biomarkers for the diagnosis and treatment response of AD.
\end{abstract}

KEY WORDS: Alzheimer disease; Receptors, N-methyl-D-aspartate; Oxidative stress.

\section{INTRODUCTION OF ALZHEIMER'S DISEASE (AD)}

As advancement of technology and elevating medical standard, mankind can live longer life than our ancients. Accompanied with longevity, we face aging among all of the organs, including brain. $A D$, the most common type of

Received: October 15, 2020 / Revised: December 7, 2020

Accepted: December 14, 2020

Address for correspondence: Chieh-Hsin Lin

Department of Psychiatry, Kaohsiung Chang Gung Memorial

Hospital, Chang Gung University College of Medicine, No. 123,

Dapi Rd., Niaosong District, Kaohsiung 833, Taiwan

E-mail: cyndi36@gmail.com

ORCID: https://orcid.org/0000-0001-6949-8968

Hsien-Yuan Lane

Graduate Institute of Biomedical Sciences, China Medical

University, No. 91, Hsueh-Shih Rd., North Dist., Taichung 404,

Taiwan

E-mail: hylane@gmail.com

ORCID: https://orcid.org/0000-0003-2162-8174 dementia, is a disease highly correlated with aging which featured as insidious memory impairment as well as executive dysfunction [1]. While disease progressed gradually, neuropsychiatric symptoms such as delusions, hallucinations and aggression become more common. These symptoms lead to impaired daily function, decreased quality of life and higher economic burden [2]. According to G8 statement in 2013, dementia population worldwide in 2015 was around 47.47 million, reaching 75.63 million in 2030 and 135.46 million in 2050. In 2015, it cost over $\$ 600$ billion per year for 35 million patients with dementia, equivalent to one percent of global Gross Domestic Product [3]. Caregivers of Alzheimer's and other dementias patient provided unpaid assistance which was equivalent to eight times of McDonald's total annual income in 2014. Huge care burden have adverse effect not only on economic aspects, but also emotional well-being and physical health among caregivers [4]. There are sev-

(ㄷ) This is an Open-Access article distributed under the terms of the Creative Commons Attribution Non-Commercial License (http://creativecommons.org/licenses/by-nc/4.0) which permits unrestricted non-commercial use, distribution, and reproduction in any medium, provided the original work is properly cited. 
eral advantages of early detection, including leading to attempts at therapy (both pharmacological and non-pharmacological therapies), early access to appropriate agencies or support networks and may slow the disease progressive course $[5,6]$. Moreover, based on early detection, primary and secondary prevention strategies could be developed before irreversible neuronal dysfunction and loss occur. Postponing the onset of $\mathrm{AD}$ for a few years would have a huge impact on public health [7]. It is important to identify $A D$ and provide effective treatment as early as possible, to improve patients' wellbeing and relieve disease-related adverse loading. Therefore, searching for feasible biomarkers of $\mathrm{AD}$ is crucial.

In the past decades, accumulation of abnormally folded beta-amyloid $(\mathrm{A} \beta$ ) and tau protein tangles are classical etiology of AD. As growing clinical and pathological studies being published, more and more evidences indicated that $\mathrm{AD}$ is a complex and multifactorial neurodegenerative disease [1]. Mutations at genes such as APP, PSEN1, or PSEN2 from familial studies provided the strongest evidence of $A \beta$ and tau [8]. In amyloid hypothesis, $A \beta$ deposition acts as an enhancer of pathological cascade and eventually leads to neuro fibrillary tangle of tau protein. Persistent accumulation of $A \beta$ further causes structural damage of neurons, characterized by the loss of synapses, decreasing neurons number, and brain atrophy in AD patients [9].

In mitochondrial cascade hypothesis, the interaction between mitochondrial DNA mutations, $A \beta$ in mitochondria, and oxidative stress is important in $A D$ pathogenesis [10]. $A \beta$ can interact with cyclophilin $D$ (a kind of voltage-dependent anion channel related to mitochondrial permeability pore) to potentiate mitochondrial and neuronal perturbation. This interaction results in impaired mitochondrial membrane potential, increasing oxidative stress, and consequently cellular and synaptic perturbations observed in $\mathrm{AD}$ [11].

On the other hand, cholinergic hypothesis has been testified in plenty of studies focusing on neurodegenerative diseases. Acetylcholine (ACh) is a neurotransmitter responsible for electrical impulses conduction. In patients with $A D$, level of $A C h$ is decreased due to rapid hydrolysis by acetyl cholinesterase (belonging to $\alpha / \beta$-fold family of proteins) [12].

Besides, as increasing understanding about metabolic disease, metabolic hypothesis indicated that $\mathrm{AD}$ is related to metabolic processes including obesity, diabetes, and hypercholesterolemia [13]. Several studies have demonstrated a close relationship between diabetes mellitus and AD $[14,15]$. Microvascular damage in diabetic polyneuritis with the central nervous system (CNS) changes is the most comprehensive relationship found in AD [14]. Also, insulin draws a possible pathway from peripheral system to CNS [15]. Peripherally, low-grade chronic inflammation leads to insulin resistance and tissue deterioration; centrally, synaptic dysfunction and cognitive deficits in $\mathrm{AD}$ were related to impaired insulin signaling [16]. Evidence of alterations in the expression of diabetes-related genes, insulin depletion, impaired insulin signaling, and mitochondrial dysfunction were found in AD brains [17].

Currently, there are three cerebrospinal fluid (CSF) biomarkers with potential in identifying prodromal $A D$ in the mild cognitive impairment $(\mathrm{MCl})$ stage, including $A \beta 42$, total tau (T-tau) and phosphorylated tau (P-tau) $[18,19]$. Reduced $A \beta 42$ levels, reflecting brain amyloidosis, are characteristic of $A D$ as well as prodromal $A D$ [20]. Besides, the CSF $A \beta 42 / A \beta 40$ ratio is better to identify $A D$ than CSF $A \beta 42$ alone $[21,22]$. CSF T-tau is a marker that can reflect the severity of acute brain damage and intensity of neurodegeneration [23]. As a potential biomarker for neurodegenerative diseases, CSF T-tau level is 10-20 times higher in Creutzfeldt-Jakob disease than in $A D$ [24]. When both levels are increased in CSF, T-tau, and P-tau may indicate a more rapid disease progression [25]. However, to date, these biomarkers still have disadvantages including high cost, invasiveness assays, and lack of standardized cutoffs among different laboratories $[1,26]$. Other than the three aforementioned core CSF biomarkers, some novel synaptic biomarkers such as neurogranin, synaptosomal-associated protein 25, syntaxin-1, and vesicle-associated membrane protein have been also under investigation [20]. In addition to CSF, various methods for detecting such biomarkers and their specific usage in clinical and research fields are under rapid development, including in vivo brain imaging with positron emission tomography and magnetic resonance imaging, biotechniques skin and blood cells [27]. To be less invasive, blood samples to acquire biomarkers is easier to collect than CSF. In many studies, highly heterogeneous blood profiles such as proteins, lipids and metabolites were used to differentiated AD patients from heathy individuals [28]. 
Nevertheless, these data are often overlapping between patients and controls, difficult to analyze and hardly to be replicated in different studies $[29,30]$. A recent systematic review and meta-analysis study about neurodegenerative CSF and blood biomarkers suggested that among blood biomarkers, only plasma T-tau had a large effect size to differentiate between AD patients and controls though its $p$ value was only 0.02 [31].

\section{IMPORTANCE OF TREATING AD}

Current treatment of AD can be grossly divided into two categories, pharmacological and non-pharmacological. Among pharmacological treatment, cholinesterase inhibitors (ChEl) including donepezil, galantamine, and rivastigmine as well as $\mathrm{N}$-methyl-D-aspartate receptor (NMDAR) antagonist, memantine are four Food and Drug Administration (FDA) approved medication for AD. ACh plays a key role in mediating memory and learning [32]. ChEl are now widely used in patients with mild to moderate $A D$, however, their effect is only modest [33]. Statistically significances were noted but with borderline clinically improvement while assessing global assessment of dementia and cognition function [34]. According to some comparative trials, hardly could they find consistently significant efficacy differences between the three ChEls, the main differences were frequency and type of adverse events [35].

In a recent meta-analysis and meta-regression study, ChEl had a dissatisfied risk-benefit relationship and a higher than placebo all-cause discontinuation [36]. Memantine, though frequently prescribed in moderate to severe dementia patient, according to most recent Cochrane review in 2019, it has small clinical benefit versus placebo and no benefit in mild AD [37].

Other than FDA approved medical treatment, several putative therapies are under study. However, there is no inspiring result among hormone replace therapy (HRT), folate, vitamin B12, Ginkgo biloba and statins. No convincible evident suggested these putative therapies had benefit in cognition function in people with dementia and HRT is even harmful [38].

There is no new effective treatment of AD developed in recent decades. In recent years, several huge late-phase clinical trials failed to find positive clinical outcome. In 2013, bapineuzumab, a monoclonal antibody specific to the $N$-terminus of the $A \beta$ was lack of efficacy in treating mild to moderate AD [39]. In 2016, solanezumab, another monoclonal antibody designed to increase the clearance from the brain of soluble $A \beta$ didn't significantly affect cognitive decline in mild AD patients [40]. Despite these disappointing results, a different approach by verubecestat, a $\beta$-site amyloid precursor protein-cleaving enzyme 1 inhibitor, can reduce levels of $A \beta 40, A \beta 42$, and SAPP $\beta$ in plasma and CSF after administration to rats and monkeys [41]. However, further study in humans not only failed to reduce cognitive or functional decline in patients with mild-to-moderate AD but also brought treatment-related adverse events [42]. Moreover, in prodromal AD, patients under verubecestat even had worse cognition and daily function than control individuals in some measures [43]. In early 2019, a clinical trial of crenezumab (a immunoglobulin isotype G4 monoclonal antibody designed under the hypothesis of this antibody with reduced effector function would have a lower risk of inducing amyloid-related imaging abnormalities indicative of vasogenic edema or effusions and microhemorrhage and siderosis) in prodromal to mild AD patients was terminated under the recommendation of the Independent Data Monitoring Committee $[44,45]$. The committee suggested that crenezumab was unlikely to meet the primary endpoint of change from baseline in Clinical Dementia Rating-Sum of Boxes [45]. Besides, another trial of antibody that targets oligomers and fibrils of $A \beta$, aducanumab, once the most promising candidate, was terminated in March, 2019, owing to unlikely to meet their primary endpoint upon completion [46]. Though determination of these late phase clinical trials is quite frustrated, hundreds of clinical trials are still undergoing. These trials focusing on domains including not only $A \beta$ but also synaptic plasticity, metabolism and bioenergetics, vasculature, hormones, inflammation and oxidative stress [47]. As Selkoe [48] said, "we obviously have no choice but to redouble our efforts to understand more deeply all facets of the biological process of AD and to identify more effective therapeutic agents as quickly as possible."

Several articles pointed out that brain stimulation techniques are developing as promising tools for neurodegenerative diseases. Non-invasive brain stimulation techniques provide a reliable method to improve cognitive decline in healthy older adults and AD patients [49]. On the other hand, invasive brain stimulation such as 
deep brain stimulation and vagus nerve stimulation yielded inconsistent results in AD patients [50,51]. Generally, brain stimulation techniques may shed light on novel treatment of improving specific cognitive function and memory; however, due to no standard guidelines and protocols, it is still an immature field [51].

Some rehabilitation approaches including music and exercise therapies may benefit cognitive, emotional and behavioral symptoms in $\mathrm{AD}$ patient. Due to relative small data, more researches are needed to be done to confirm the effectiveness and impact to the disease $[52,53]$.

\section{GLUTAMATE THEORY, FOCUSING ON NMDAR}

In the past decades, researches have munificent evidence suggested that beta-amyloid $(A \beta)$ and tau protein abnormally accumulation in amyloid plaques and intracellular neurofibrillary tangles respectively are hallmark pathologies of AD [54]. However, therapies aiming at the clearance of $A \beta$ failed to date $[39,40]$. As growing studies indicated different hypothesis and possible pathophysiology of dementia, we now believe that dementia is a multifactorial disease with complex network $[55,56]$.

Glutamate is a critical excitatory neurotransmitter in mammalian CNS. It regulates neurogenesis, neurite outgrowth, synaptogenesis, and neuron survival. Also, glutamate interacts with neurotrophic factors to modulate neuroplasticity [57]. Glutamine-glutamate cycle is also related to several psychiatric diseases such as major depressive disorder (MDD), schizophrenia, and AD. A recent study in elderly individuals with MDD showed that the ratio of glutamine to glutamate was significantly higher at baseline than in controls. Moreover, the ratio decreased over the 3-year follow-up, and the reduction was correlated with a decrease in the severity of depression [58]. A newly published nationwide longitudinal study in Taiwan also indicated that late-onset (age $>65$ years) treatmentresistant depression was associated with an elevated risk of $\mathrm{AD}$ [59].

At most excitatory synapses, NMDAR, an ion-channel receptor, could be found and responds to the neurotransmitter glutamate [60]. It is an essential neurotransmitter receptor not only as an excitatory neurotransmission but also to the intricacy of memory and learning [61]. Besides, it owns special properties and plays an important role in synaptic plasticity. Impairment of NMDAR is associated with multiple pathologies of neuropsychiatric disease, for instance, schizophrenia and AD [62].

\section{NMDAR Hypoactivation and AD}

Under physiological condition, NMDAR is blocked by magnesium (Mg) ion. UpCon glutamate binding to NMDAR, the $\mathrm{Mg}$ block ends and the receptor activates, calcium and sodium flow into cells via NMDA channels. Several mechanisms exist to protect this route to prevent hyperactivation; however, during some acute brain damages (e.g., ischemia, hypoxia) or chronic brain pathology (e.g., $A D)$, NMDAR overacts, leading to excitotoxicity and cause neural death [63].

On the contrary, NMDAR hypoactivation also generates neurological disorders. Newcomer et al. [64] hypothesized that in AD patients, NMDAR follows a two-stage process leading to cognitive disturbances. In the first stage, $A \beta$ interacts with NMDAR causing hyperactivation and disinhibition processes to several excitatory pathways which terminate in posterior cingulated and retrosplenial cortical regions and further result in NMDAR hypoactivation status. Then, glutamatergic activation is depressed and synaptic components are downregulated [65]. This hypothesis was supported by hippocampal dynamic model which shows hippocampal hyperactivation occurring before hypoactivation during $\mathrm{MCl}$ and both lead to cognitive impairment $[66,67]$. Although hypofunction of NMDAR appears in normal brain aging, in AD patients, this process interacts with other pathogenesis (e.g., amyloidopathy and oxidative stress) and increase NMDAR hypofunction loading [64]. Human study revealed significant decreased NMDAR1 messenger RNA levels in Alzheimer brains, comparing to age-controlled individuals, suggesting certain change is specific for the disease itself [68]. A study focusing on NMDAR synaptic plasticity among $A D$ rat model found that blocking NMDAR in rats' hippocampi resulted in electrophysiological and behavioral changes, thereby altering long-term potentiation and long-term depression. These researches pointed a possible way to treat $\mathrm{AD}$ from the aspect of receptor function rather than neurotransmitter or nerve cells apoptosis [69].

\section{Oxidative Stress and AD}

Since 20th century, oxidative stress has been regarded as a crucial factor in differentiation and aging. The level of 
oxidative stress is linked to the rate of aging and altered gene expression during the process [70]. Though there is doubt in regarding oxidative stress as a possible etiology causes $\mathrm{AD}$ and some researchers take it as a physiologically phenomenon, increasing biomarkers were found correlated to $\mathrm{AD}$ or $\mathrm{MCl}$ recently $[71,72]$. Two species, reactive nitrogen species and reactive oxygen species (ROS) can modify biological properties of the cell membrane and eventually generate new oxidized products that can be measured in peripheral fluids as an oxidative stress index [71].

Mitochondria are the energy source of most cellular reaction by undergoing aerobic metabolism in the brain. Mitochondrial dysfunction, leading to overproduction of ROS, is related to sporadic, late-onset AD [73]. Besides, early mitochondrial dysfunction was found in not only animal but also human AD individuals [74-78]. Imbalanced ROS production and antioxidant defense alter cellular interaction at early aging process, prior to detectable clinical symptoms and even $A \beta$ pathology [79].

Brain tissue is abundant of polyunsaturated fatty acids which may interact with ROS [80]. Elevated unstable lipid hydroperoxides products such as lipid hydroperoxides products such as malondialdehyde and 4-hydroxynonenal were detected in patients with $\mathrm{AD}$ and $\mathrm{MCl}$ [81-83]. Various animal experiments showed that lipid peroxidation exceeded $A \beta$ pathology [84]. The possible mechanism may be associated with triggering hydroxynonenalor iron (Fe)-activated $\gamma$-secretase activity [85].

Other than mitochondrial dysfunction and lipid peroxidation, several bioactive metals like zinc ( $\mathrm{Zn}), \mathrm{Mg}$, Fe, copper $(\mathrm{Cu})$, aluminum, and manganese were also related to oxidative stress influencing $A \beta$ and Tau aggregation $[86,87]$. In AD patients, abnormal levels of $\mathrm{Zn}, \mathrm{Cu}$, and $\mathrm{Fe}$ were observed within severe histopathological changes in amygdala, hippocampus, and other brain regions [88]. By different techniques, elevated $\mathrm{Fe}, \mathrm{Cu}$, and $\mathrm{Zn}$ levels were found in mouse models of $A D$ and $A D$ patients' amyloid plaques brain tissue [89-92]. On the other hand, Fe interacts with homocysteine, a kind of non-protein amino acid that elevates in $\mathrm{AD}$ patients' plasma and serum, resulting in increased protein carbonylation and leading to oxidative damage [84].

\section{Interaction between NMDAR Hypoactivation and Oxidative Stress}

Various studies have revealed relationship between NMDAR hypoactivation and oxidative stress. In normal physiological condition, NMDARs have redox sites [93]. Synaptic NMDAR function under neuronal antioxidant defense mechanisms is activated [94]. There are different redox state subunits on NMDAR, for instance, glutamate ionotropic NMDAR type subunit 1 (GRIN1) and GRIN2A. Especially among GRIN2A-containing NMDARs, the redox regulation is powerful. By reducing agents such as antioxidant glutathione (GSH) or dithiothreitol, a region of the $\mathrm{N}$-terminus is sufficient to mediate the potentiation of currents $[95,96]$. Temporal GSH deficits are able to induce NMDAR hypofunction [97]. Importantly, the relationship between NMDAR hypofunction, oxidative stress, and GSH deficits is reciprocal $[98,99]$. Besides, GRIN1 was found with increment of ROS levels and down-regulation of the regulator in mitochondrial energy metabolism and antioxidant defenses [100] (Fig. 1). Other than these oxidative-sensitive site subunits, functional down regulation of NMDAR is also related to calcium ion/calmodulin-dependent protein kinase II (CaMKII), which is responsible for NMDAR redox sensitivity and trafficking of glutamate receptors at the synapse [101]. Age-related intracellular redox state difference, which is linked to NMDAR activity, can be regulated by CaMKII and rescued by intracellular GSH [102]. In MCl and AD hippocampi, active CaMKII immunoreactivity redistribution correlates with cognitive assessment scores [103].

Parvalbumin interneurons $(\mathrm{PVI})$ are GABAergic neurons that form inhibitory synapses to pyramidal neurons [104]. Studies from Jiang et al. [100] indicate that redox dysregulation impairs maturation of PVI induced by NMDAR hypofunction. Some studies in mice suggest that NMDAR hypofunction may weaken antioxidant defenses, further yielding a redox imbalance and altering cell maturation $[100,105,106]$. In developing mouse model, relatively mild transient NMDAR hypofunction may hamper PVI function permanently $[106,107]$. The underlying mechanism eventually generate $\mathrm{H}_{2} \mathrm{O}_{2}$ [107]. Both NMDAR hypofunction and oxidative stress contribute to selective $\mathrm{PVI}$ functional disturbance as well as cognitive and behavioral impairment [108]. Combination of cellular-level and circuit effects of NMDAR hypofunction can exacerbate oxidative stress [108]. 


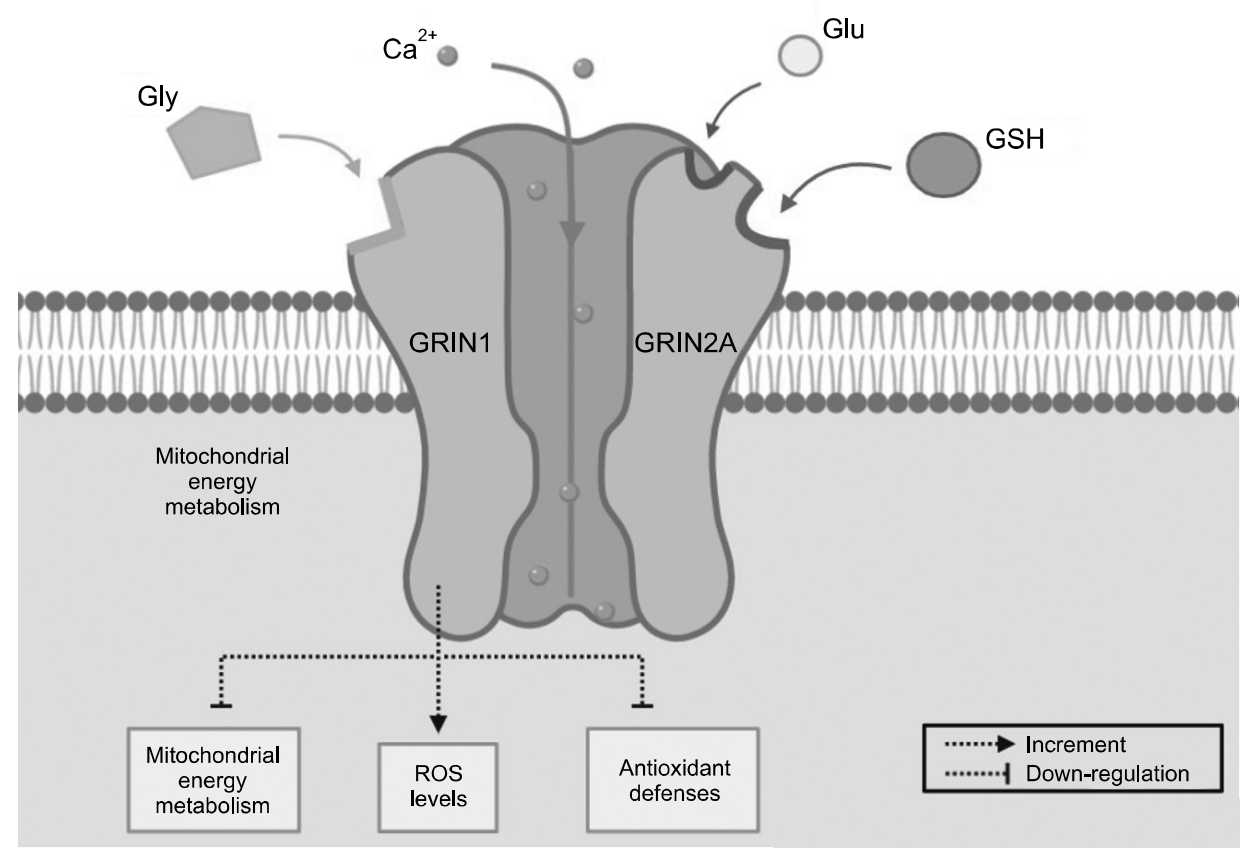

Fig. 1. Relationship between N-methyl-D-aspartate receptor (NMDAR) hypoactivation and oxidative stress. NMDARs have redox sites, including glutamate ionotropic NMDAR type subunit 1 (GRIN1) and GRIN2A. Glutathione (GSH) can mediate the potentiation of currents. GRIN1 can increase reactive oxygen species (ROS) levels and down-regulate the mitochondrial energy metabolism and antioxidant defenses.

Glu, glutamate; Gly, glycine; Ca, calcium.

\section{NMDAR Enhancer and Its Role in AD}

Based upon the aforementioned studies, it is evident that NMDARs play important roles not only in synaptic plasticity, learning, memory, cognition, but also in the aging brain. Some mood and behavior symptoms of AD are similar to negative symptoms of schizophrenia, for instance, social withdrawal and apathy. In schizophrenia patients, the positive symptoms such as delusion, hallucination, disorganized speech and disturbing behavior, resemble some clinical manifestations in middle-stage AD. Previous studies showed that improvement of behavior and memory symptoms could be observed with administration of enhancers of NMDA neurotransmission [109,110]. However, there are controversial findings about whether D-cycloserine (a partial agonist of the NMDAR-glycine site) could improve dementia patients' cognitive function [111-114]. Compared to D-cycloserine, D-serine is a more potent NMDAR co-agonist. Several clinical trials suggest that, with large amount, D-serine and D-cycloserine as an adjunctive therapy in schizophrenia patients may be able to improve positive, negative, or cognitive symptoms [115, 116]. There are abundant researches exploring the relationship between $\mathrm{AD}$ and $\mathrm{D}$-serine level in serum or CSF.
The results were controversial. Earlier research with smaller sample size showed that serum levels of D-serine in $\mathrm{AD}$ patients were slightly lower than those of normal controls [117]. In more recent studies, elevated D-serine levels were found in post-mortem $A D$ brains as well as CSF of probable AD patients, however, the results failed to be confirmed in other studies [118,119]. Different from previous studies which recruited medicated AD patients, a newly published cohort study which enrolled whole clinical spectrum of drug-free AD patients with bigger sample size revealed indistinguishable CSF and serum D-serine levels and D-serine/total serine ratio compared to controls [120].

D-amino acid oxidase (DAAO), an enzyme, found in mammals' brain, kidney, and liver, is responsible for degrading D-serine and other D-amino acids [121,122]. Sodium benzoate, a DAAO inhibitor, can increase synaptic concentrations of D-serine and then enhance NMDAR neurotransmission [123]. A 6-week, randomized, double-blind, placebo-controlled clinical trial revealed that sodium benzoate $(1 \mathrm{~g} /$ day $)$ as an adjunctive therapy in chronic schizophrenia patients significantly improved not only in positive and negative symptoms, but also cogni- 
tive functions, such as processing speed and visual memory [110]. Furthermore, a 24-week randomized, double-blind, placebo-controlled trial of sodium benzoate substantially improved cognitive and overall functions in early-phase AD. Besides, these patients tolerated sodium benzoate $250-1,500 \mathrm{mg} /$ day well without obvious side effects [124].

\section{SUMMARY}

As aging society is coming, growing numbers of older adults suffer from AD. Gradually declining memory and cognitive function lead to significant impairment in their daily life and result in huge burden upon caregivers as well as national finance. The efficacy of current FDA approved four medications including donepezil, galantamine, rivastigmine, and memantine for $\mathrm{AD}$ is not satisfied. Therefore, new effective treatment is urgently needed. $A D$, as an age-related progressively neurodegenerative disease displays complex pathogenesis leading to abnormal accumulation of $A \beta$ and tau protein; however, numerous clinical trials have failed, suggesting there are more delicate interaction between neurotransmitters, synapse activity and many other factors.

In this article, we reviewed novel biomarkers of AD, especially based on the aspect from NMDAR hypoactivation and oxidative stress. Studies in both mouse and human models suggest that there is significant interaction between NMDAR hypoactivation and oxidative stress, further related to cognitive disintegration. These biomarkers may be considered as potential keys to develop new diagnostic tools or treatments for AD.

\section{Acknowledgments}

This work was supported by National Health Research Institutes, Taiwan (NHRI-EX108-10816NC; NHRI-EX10910731NI; NHRI-EX109-10816NC; NHRI-EX110-10816NC), Ministry of Science and Technology in Taiwan (MOST 109-2628-B-182A-002-; MOST 108-2628-B-182A-002; MOST 107-2628-B-182A-002; MOST 106-2314-B-182A088-MY3), Chang Gung Memorial Hospital (CMRPG8G 1391), China Medical University (CMU109-MOST-03), China Medical University Hospital (DMR-110-126).

\section{Conflicts of Interest}

No potential conflict of interest relevant to this article was reported.

\section{Author Contributions}

Hsien-Yuan Lane and Chieh-Hsin Lin conceived and designed the manuscript, drafted the manuscript, and approved the final version of manuscript. Ting-I Chiang and Yi-Hsiang Yu analyzed and interpreted data and drafted the manuscript.

\section{ORCID}

Ting-I Chiang

Yi-Hsiang Yu

Chieh-Hsin Lin

https://orcid.org/0000-0001-7548-0967

Hsien-Yuan Lane https://orcid.org/0000-0001-9478-2733 https://orcid.org/0000-0001-6949-8968 https://orcid.org/0000-0003-2162-8174

\section{REFERENCES}

1. Scheltens P, Blennow K, Breteler MM, de Strooper B, Frisoni GB, Salloway S, et al. Alzheimer's disease. Lancet 2016; 388:505-517.

2. Lyketsos CG, Carrillo MC, Ryan JM, Khachaturian AS, Trzepacz P, Amatniek J, et al. Neuropsychiatric symptoms in Alzheimer's disease. Alzheimers Dement 2011;7:532-539.

3. Marešová P, Mohelská H, Dolejš J, Kuča K. Socio-economic aspects of Alzheimer's disease. Curr Alzheimer Res 2015; 12:903-911.

4. Alzheimer's Association. 2016 Alzheimer's disease facts and figures. Alzheimers Dement 2016;12:459-509.

5. National Institute of Diabetes and Digestive and Kidney Diseases. LiverTox: clinical and research information on drug-induced liver injury. Bethesda:National Institute of Diabetes and Digestive and Kidney Diseases;2012.

6. Maki Y, Yamaguchi H. Early detection of dementia in the community under a community-based integrated care system. Geriatr Gerontol Int 2014;14 Suppl 2:2-10.

7. Crous-Bou M, Minguillón C, Gramunt N, Molinuevo JL. Alzheimer's disease prevention: from risk factors to early intervention. Alzheimers Res Ther 2017;9:71.

8. Karch CM, Goate AM. Alzheimer's disease risk genes and mechanisms of disease pathogenesis. Biol Psychiatry 2015; 77:43-51.

9. Barage SH, Sonawane KD. Amyloid cascade hypothesis: pathogenesis and therapeutic strategies in Alzheimer's disease. Neuropeptides 2015;52:1-18.

10. Jellinger KA. Basic mechanisms of neurodegeneration: a critical update. J Cell Mol Med 2010;14:457-487.

11. Rao VK, Carlson EA, Yan SS. Mitochondrial permeability transition pore is a potential drug target for neurodegeneration. Biochim Biophys Acta 2014;1842:1267-1272.

12. Ramirez Diaz SP. Enfermedad de Alzheimer. Presente y futuro. Mexico City:PyDESA;2011.

13. Mendiola-Précoma J, Rodríguez-Cruz A, Berumen L, García- 
Alcocer G. The etiology of Alzheimer's disease [Internet]. SMGroup; 2016 Aug 30 [cited at 2019 Sep 28]. Available from: https://smjournals.com/ebooks/Neurobiology/chapters/NB-16-01.pdf.

14. Domínguez RO, Pagano MA, Marschoff ER, González SE, Repetto MG, Serra JA. Alzheimer disease and cognitive impairment associated with diabetes mellitus type 2: associations and a hypothesis. Neurologia 2014;29:567-572.

15. Sandhir R, Gupta S. Molecular and biochemical trajectories from diabetes to Alzheimer's disease: a critical appraisal. World J Diabetes 2015;6:1223-1242.

16. Jayaraj RL, Azimullah S, Beiram R. Diabetes as a risk factor for Alzheimer's disease in the Middle East and its shared pathological mediators. Saudi J Biol Sci 2020;27:736-750.

17. Nakabeppu Y. Molecular pathophysiology of insulin depletion, mitochondrial dysfunction, and oxidative stress in Alzheimer's disease brain. Adv Exp Med Biol 2019;1128: 27-44.

18. Shaw LM, Vanderstichele H, Knapik-Czajka M, Clark CM, Aisen PS, Petersen RC, et al. Cerebrospinal fluid biomarker signature in Alzheimer's disease neuroimaging initiative subjects. Ann Neurol 2009;65:403-413.

19. Visser PJ, Verhey F, Knol DL, Scheltens P, Wahlund LO, Freund-Levi Y, et al. Prevalence and prognostic value of CSF markers of Alzheimer's disease pathology in patients with subjective cognitive impairment or mild cognitive impairment in the DESCRIPA study: a prospective cohort study. Lancet Neurol 2009;8:619-627.

20. Blennow K, Zetterberg H. Biomarkers for Alzheimer's disease: current status and prospects for the future. J Intern Med 2018;284:643-663.

21. Hansson $\mathrm{O}$, Zetterberg $\mathrm{H}$, Buchhave $\mathrm{P}$, Andreasson $\mathrm{U}$, Londos E, Minthon L, et al. Prediction of Alzheimer's disease using the CSF Abeta42/Abeta4O ratio in patients with mild cognitive impairment. Dement Geriatr Cogn Disord 2007; 23:316-320.

22. Wiltfang J, Esselmann $\mathrm{H}$, Bibl M, Hüll M, Hampel $\mathrm{H}$, Kessler $\mathrm{H}$, et al. Amyloid beta peptide ratio 42/40 but not $A$ beta 42 correlates with phospho-Tau in patients with low- and high-CSF A beta 40 load. I Neurochem 2007;101:10531059.

23. Blennow K, Hampel H. CSF markers for incipient Alzheimer's disease. Lancet Neurol 2003;2:605-613.

24. Riemenschneider M, Wagenpfeil S, Vanderstichele H, Otto M, Wiltfang J, Kretzschmar H, et al. Phospho-tau/total tau ratio in cerebrospinal fluid discriminates Creutzfeldt-Jakob disease from other dementias. Mol Psychiatry 2003;8:343347.

25. Wallin AK, Blennow K, Zetterberg H, Londos E, Minthon L, Hansson O. CSF biomarkers predict a more malignant outcome in Alzheimer disease. Neurology 2010;74:15311537.

26. Hampel H, O’Bryant SE, Molinuevo JL, Zetterberg H, Masters
CL, Lista S, et al. Blood-based biomarkers for Alzheimer disease: mapping the road to the clinic. Nat Rev Neurol 2018; 14:639-652.

27. Khan TK, Alkon DL. Peripheral biomarkers of Alzheimer's disease. J Alzheimers Dis 2015:44:729-744.

28. Henriksen K, O’Bryant SE, Hampel H, Trojanowski JQ, Montine TJ, Jeromin A, et al. The future of blood-based biomarkers for Alzheimer's disease. Alzheimers Dement 2014; 10:115-131.

29. O’Bryant SE, Gupta V, Henriksen K, Edwards M, Jeromin A, Lista $S$, et al. Guidelines for the standardization of preanalytic variables for blood-based biomarker studies in Alzheimer's disease research. Alzheimers Dement 2015;11: 549-560.

30. Zhao X, Lejnine S, Spond J, Zhang C, Ramaraj TC, Holder DJ, et al. A candidate plasma protein classifier to identify Alzheimer's disease. J Alzheimers Dis 2015;43:549-563.

31. Olsson B, Lautner R, Andreasson U, Öhrfelt A, Portelius E, Bjerke M, et al. CSF and blood biomarkers for the diagnosis of Alzheimer's disease: a systematic review and metaanalysis. Lancet Neurol 2016;15:673-684.

32. Mitsushima D, Sano A, Takahashi T. A cholinergic trigger drives learning-induced plasticity at hippocampal synapses. Nat Commun 2013;4:2760.

33. Kaduszkiewicz H, Zimmermann T, Beck-Bornholdt HP, van den Bussche $\mathrm{H}$. Cholinesterase inhibitors for patients with Alzheimer's disease: systematic review of randomised clinical trials. BMJ 2005;331:321-327.

34. Raina $P$, Santaguida P, Ismaila A, Patterson C, Cowan D, Levine M, et al. Effectiveness of cholinesterase inhibitors and memantine for treating dementia: evidence review for a clinical practice guideline. Ann Intern Med 2008; 148:379-397.

35. O'Brien JT, Burns A. Clinical practice with anti-dementia drugs: a revised (second) consensus statement from the British Association for Psychopharmacology. I Psychopharmacol 2011;25:997-1019.

36. Blanco-Silvente L, Castells X, Saez M, Barceló MA, GarreOlmo J, Vilalta-Franch J, et al. Discontinuation, efficacy, and safety of cholinesterase inhibitors for Alzheimer's disease: a meta-analysis and meta-regression of 43 randomized clinical trials enrolling 16106 patients. Int J Neuropsychopharmacol 2017;20:519-528.

37. McShane R, Westby MJ, Roberts E, Minakaran N, Schneider $\mathrm{L}$, Farrimond LE, et al. Memantine for dementia. Cochrane Database Syst Rev 2019;3:CD003154.

38. O’Brien JT, Holmes C, Jones M, Jones R, Livingston G, McKeith I, et al. Clinical practice with anti-dementia drugs: a revised (third) consensus statement from the British Association for Psychopharmacology. I Psychopharmacol 2017; 31:147-168.

39. Vandenberghe $R$, Rinne JO, Boada M, Katayama S, Scheltens $\mathrm{P}$, Vellas B, et al. Bapineuzumab for mild to moderate Alzheimer's disease in two global, randomized, phase 
3 trials. Alzheimers Res Ther 2016;8:18.

40. Honig LS, Vellas B, Woodward M, Boada M, Bullock R, Borrie $\mathrm{M}$, et al. Trial of solanezumab for mild dementia due to Alzheimer's disease. N Eng/ J Med 2018;378:321-330.

41. Kennedy ME, Stamford AW, Chen X, Cox K, Cumming JN, Dockendorf MF, et al. The BACE1 inhibitor verubecestat (MK-8931) reduces CNS $\beta$-amyloid in animal models and in Alzheimer's disease patients. Sci Trans/Med 2016;8:363ra150.

42. Egan MF, Kost J, Tariot PN, Aisen PS, Cummings JL, Vellas B, et al. Randomized trial of verubecestat for mild-to-moderate Alzheimer's disease. N Eng/ J Med 2018;378:1691-1703.

43. Egan MF, Kost J, Voss T, Mukai Y, Aisen PS, Cummings JL, et al. Randomized trial of verubecestat for prodromal Alzheimer's disease. N Eng/ / Med 2019;380:1408-1420.

44. Cummings JL, Cohen S, van Dyck CH, Brody M, Curtis C, Cho W, et al. ABBY: A phase 2 randomized trial of crenezumab in mild to moderate Alzheimer disease. Neurology 2018;90:e1889-e1897.

45. Genentech's crenezumab fails two phase III trials in Alzheimer's 2019 [Internet]. Genetic Engineering \& Biotechnology News; 2019 Jan 30 [cited at 2019 Sep 28]. Available from: https://www.genengnews.com/news/genentechs-crenezumab-fails-two-phase-iii-trials-in-alzheimers/.

46. Molano JRV. Trials of promising Alzheimer drug stopped [Internet]. NEJM Journal Watch; 2019 Apr 12 [cited at 2019 Sep 28]. Available from: https://www.jwatch.org/na48888/ 2019/04/12/trials-promising-alzheimer-drug-stopped.

47. Ongoing Alzheimers and related clinical trials and studies [Internet]. National Institute on Aging; 2019 [updated 2020 Dec 4; cited at 2019 Sep 28]. Available from: https://www. nia.nih.gov/research/ongoing-AD-trials\#top.

48. Selkoe DJ. Alzheimer disease and aducanumab: adjusting our approach. Nat Rev Neurol 2019;15:365-366.

49. Hsu WY, Ku Y, Zanto TP, Gazzaley A. Effects of noninvasive brain stimulation on cognitive function in healthy aging and Alzheimer's disease: a systematic review and meta-analysis. Neurobiol Aging 2015;36:2348-2359.

50. Aldehri M, Temel Y, Alnaami I, Jahanshahi A, Hescham S. Deep brain stimulation for Alzheimer's Disease: an update. Surg Neurol Int 2018;9:58.

51. Chang $\mathrm{CH}$, Lane HY, Lin CH. Brain stimulation in Alzheimer's disease. Front Psychiatry 2018;9:201.

52. Garcia-Casares N, Moreno-Leiva RM, Garcia-Arnes JA. [Music therapy as a non-pharmacological treatment in Alzheimer's disease. A systematic review]. Rev Neurol 2017;65:529538. Spanish.

53. Maliszewska-Cyna E, Lynch M, Oore JJ, Nagy PM, Aubert I. The benefits of exercise and metabolic interventions for the prevention and early treatment of Alzheimer's disease. Curr Alzheimer Res 2017;14:47-60.

54. Karran E, Mercken M, De Strooper B. The amyloid cascade hypothesis for Alzheimer's disease: an appraisal for the development of therapeutics. Nat Rev Drug Discov 2011;10:
698-712.

55. Boyle PA, Wilson RS, Yu L, Barr AM, Honer WG, Schneider $\mathrm{JA}$, et al. Much of late life cognitive decline is not due to common neurodegenerative pathologies. Ann Neurol 2013; 74:478-489.

56. Mendiola-Precoma J, Berumen LC, Padilla K, Garcia-Alcocer G. Therapies for prevention and treatment of Alzheimer's disease. Biomed Res Int 2016;2016:2589276.

57. Mattson MP. Glutamate and neurotrophic factors in neuronal plasticity and disease. Ann N Y Acad Sci 2008;1144: 97-112.

58. Hashimoto K, Bruno D, Nierenberg J, Marmar CR, Zetterberg $\mathrm{H}$, Blennow K, et al. Abnormality in g/utamine-g/utamate cycle in the cerebrospinal fluid of cognitively intact elderly individuals with major depressive disorder: a 3-year follow-up study. Trans/ Psychiatry 2016;6:e744.

59. Chan YE, Chen MH, Tsai SJ, Bai YM, Tsai CF, Cheng CM, et al. Treatment-resistant depression enhances risks of dementia and Alzheimer's disease: a nationwide longitudinal study. J Affect Disord 2020;274:806-812.

60. Husi H. NMDA receptors, neural pathways, and protein interaction databases. Int Rev Neurobiol 2004;61:49-77.

61. Zito K, Scheuss V. NMDA receptor function and physiological modulation. In: Squire LR, editor. Encyclopedia of neuroscience. Oxford:Academic Press;2009. p.1157-1164.

62. Miller SL, Yeh HH. Neurotransmitters and neurotransmission in the developing and adult nervous system. In: Conn PM, editor. Conn's translational neuroscience. San Diego:Academic Press;2017. p.49-84.

63. Albensi BC. The NMDA receptor/ion channel complex: a drug target for modulating synaptic plasticity and excitotoxicity. Curr Pharm Des 2007; 13:3185-3194.

64. Newcomer JW, Farber NB, Olney JW. NMDA receptor function, memory, and brain aging. Dialogues Clin Neurosci 2000;2:219-232.

65. Findley CA, Bartke A, Hascup KN, Hascup ER. Amyloid beta-related alterations to g/utamate signaling dynamics during Alzheimer's disease progression. ASN Neuro 2019;11: 1759091419855541.

66. Aizenstein HJ, Klunk WE. Where is hippocampal activity in the cascade of Alzheimer's disease biomarkers? Brain 2015; 138(Pt 4):831-833.

67. Huijbers W, Mormino EC, Schultz AP, Wigman S, Ward AM, Larvie $\mathrm{M}$, et al. Amyloid- $\beta$ deposition in mild cognitive impairment is associated with increased hippocampal activity, atrophy and clinical progression. Brain 2015;138(Pt 4): 1023-1035.

68. Ulas J, Cotman CW. Decreased expression of N-methyl-Daspartate receptor 1 messenger $R N A$ in select regions of Alzheimer brain. Neuroscience 1997;79:973-982.

69. Zhang J, Li Y, Xu J, Yang Z. The role of N-methyl-D-aspartate receptor in Alzheimer's disease. J Neurol Sci 2014;339:123129. 
70. Sohal RS, Allen RG. Oxidative stress as a causal factor in differentiation and aging: a unifying hypothesis. Exp Gerontol 1990;25:499-522.

71. García-Blanco A, Baquero M, Vento M, Gil E, Bataller L, Cháfer-Pericás C. Potential oxidative stress biomarkers of mild cognitive impairment due to Alzheimer disease. J Neurol Sci 2017;373:295-302.

72. Pohanka M. Oxidative stress in Alzheimer disease as a target for therapy. Bratis/ Lek Listy 2018;119:535-543.

73. Swerdlow RH, Burns JM, Khan SM. The Alzheimer's disease mitochondrial cascade hypothesis: progress and perspectives. Biochim Biophys Acta 2014;1842:1219-1231.

74. Beal MF. Mitochondria take center stage in aging and neurodegeneration. Ann Neurol 2005;58:495-505.

75. Du H, Guo L, Yan S, Sosunov AA, McKhann GM, Yan SS. Early deficits in synaptic mitochondria in an Alzheimer's disease mouse model. Proc Natl Acad Sci U S A 2010;107: 18670-18675.

76. Bubber P, Haroutunian V, Fisch G, Blass JP, Gibson GE. Mitochondrial abnormalities in Alzheimer brain: mechanistic implications. Ann Neurol 2005;57:695-703.

77. Reddy PH. Abnormal tau, mitochondrial dysfunction, impaired axonal transport of mitochondria, and synaptic deprivation in Alzheimer's disease. Brain Res 2011;1415:136148.

78. Caldwell CC, Yao J, Brinton RD. Targeting the prodromal stage of Alzheimer's disease: bioenergetic and mitochondrial opportunities. Neurotherapeutics 2015;12:66-80.

79. Uttara B, Singh AV, Zamboni P, Mahajan RT. Oxidative stress and neurodegenerative diseases: a review of upstream and downstream antioxidant therapeutic options. Curr Neuropharmacol 2009; 7:65-74.

80. Chen Z, Zhong C. Oxidative stress in Alzheimer's disease. Neurosci Bull 2014;30:271-281.

81. Lovell MA, Ehmann WD, Butler SM, Markesbery WR. Elevated thiobarbituric acid-reactive substances and antioxidant enzyme activity in the brain in Alzheimer's disease. Neurology 1995:45:1594-1601.

82. Butterfield DA, Reed T, Perluigi M, De Marco C, Coccia R, Cini $\mathrm{C}$, et al. Elevated protein-bound levels of the lipid peroxidation product, 4-hydroxy-2-nonenal, in brain from persons with mild cognitive impairment. Neurosci Lett 2006; 397:170-173.

83. Keller JN, Schmitt FA, Scheff SW, Ding Q, Chen Q, Butterfield DA, et al. Evidence of increased oxidative damage in subjects with mild cognitive impairment. Neurology 2005;64: 1152-1156.

84. Poprac P, Jomova K, Simunkova M, Kollar V, Rhodes CJ, Valko M. Targeting free radicals in oxidative stress-related human diseases. Trends Pharmacol Sci 2017;38:592-607.

85. Gwon AR, Park JS, Arumugam TV, Kwon YK, Chan SL, Kim $\mathrm{SH}$, et al. Oxidative lipid modification of nicastrin enhances amyloidogenic $\gamma$-secretase activity in Alzheimer's disease.
Aging Cell 2012;11:559-568.

86. Greenough MA, Camakaris J, Bush Al. Metal dyshomeostasis and oxidative stress in Alzheimer's disease. Neurochem Int 2013;62:540-555.

87. Wang P, Wang ZY. Metal ions influx is a double edged sword for the pathogenesis of Alzheimer's disease. Ageing Res Rev 2017;35:265-290.

88. Deibel MA, Ehmann WD, Markesbery WR. Copper, iron, and zinc imbalances in severely degenerated brain regions in Alzheimer's disease: possible relation to oxidative stress. J Neurol Sci 1996;143:137-142.

89. Lovell MA, Robertson JD, Teesdale WJ, Campbell JL, Markesbery WR. Copper, iron and zinc in Alzheimer's disease senile plaques. J Neurol Sci 1998;158:47-52.

90. Friedlich AL, Lee JY, van Groen T, Cherny RA, Volitakis I, Cole TB, et al. Neuronal zinc exchange with the blood vessel wall promotes cerebral amyloid angiopathy in an animal model of Alzheimer's disease. I Neurosci 2004;24:34533459.

91. Lee JY, Mook-Jung I, Koh JY. Histochemically reactive zinc in plaques of the Swedish mutant beta-amyloid precursor protein transgenic mice. J Neurosci 1999; 19:RC10.

92. Suh SW, Jensen KB, Jensen MS, Silva DS, Kesslak PJ, Danscher $\mathrm{G}$, et al. Histochemically-reactive zinc in amyloid plaques, angiopathy, and degenerating neurons of Alzheimer's diseased brains. Brain Res 2000;852:274-278.

93. Choi Y, Chen HV, Lipton SA. Three pairs of cysteine residues mediate both redox and $\mathrm{Zn}^{2+}$ modulation of the nmda receptor. J Neurosci 2001;21:392-400.

94. Hardingham GE, Bading H. Synaptic versus extrasynaptic NMDA receptor signalling: implications for neurodegenerative disorders. Nat Rev Neurosci 2010;11:682-696.

95. Choi YB, Lipton SA. Identification and mechanism of action of two histidine residues underlying high-affinity $\mathrm{Zn}^{2+}$ inhibition of the NMDA receptor. Neuron 1999;23:171-180.

96. Köhr G, Eckardt S, Lüddens $\mathrm{H}$, Monyer $\mathrm{H}$, Seeburg PH. NMDA receptor channels: subunit-specific potentiation by reducing agents. Neuron 1994;12:1031-1040.

97. Steullet P, Neijt HC, Cuénod M, Do KQ. Synaptic plasticity impairment and hypofunction of $N M D A$ receptors induced by g/utathione deficit: relevance to schizophrenia. Neuroscience 2006;137:807-819.

98. Radonjic NV, Knezevic ID, Vilimanovich U, Kravic-Stevovic T, Marina LV, Nikolic T, et al. Decreased g/utathione levels and altered antioxidant defense in an animal model of schizophrenia: long-term effects of perinatal phencyclidine administration. Neuropharmacology 2010,58:739-745.

99. Papadia S, Soriano FX, Léveillé F, Martel MA, Dakin KA, Hansen $\mathrm{HH}$, et al. Synaptic NMDA receptor activity boosts intrinsic antioxidant defenses. Nat Neurosci 2008;11:476487.

100. Jiang Z, Rompala GR, Zhang S, Cowell RM, Nakazawa K. Social isolation exacerbates schizophrenia-like phenotypes 
via oxidative stress in cortical interneurons. Biol Psychiatry 2013;73:1024-1034.

101. Mauceri D, Gardoni F, Marcello E, Di Luca M. Dual role of CaMKII-dependent SAP97 phosphorylation in mediating trafficking and insertion of NMDA receptor subunit NR2A. J Neurochem 2007;100:1032-1046.

102. Bodhinathan K, Kumar A, Foster TC. Intracellular redox state alters NMDA receptor response during aging through $\mathrm{Ca}^{2+} /$ calmodulin-dependent protein kinase II. J Neurosci 2010; 30:1914-1924.

103. Reese LC, Laezza F, Woltjer R, Taglialatela G. Dysregulated phosphorylation of $\mathrm{Ca}^{2+} /$ calmodulin-dependent protein kinase II- $\alpha$ in the hippocampus of subjects with mild cognitive impairment and Alzheimer's disease. I Neurochem 2011:119:791-804.

104. Steullet P, Cabungcal JH, Monin A, Dwir D, O'Donnell P, Cuenod $\mathrm{M}$, et al. Redox dysregulation, neuroinflammation, and NMDA receptor hypofunction: a "central hub" in schizophrenia pathophysiology? Schizophr Res 2016;176:41-51.

105. Belforte JE, Zsiros V, Sklar ER, Jiang Z, Yu G, Li Y, et al. Postnatal $N M D A$ receptor ablation in corticolimbic interneurons confers schizophrenia-like phenotypes. Nat Neurosci 2010;13: 76-83.

106. Powell SB, Sejnowski TJ, Behrens MM. Behavioral and neurochemical consequences of cortical oxidative stress on parvalbumin-interneuron maturation in rodent models of schizophrenia. Neuropharmacology 2012;62:1322-1331.

107. Wang X, Pinto-Duarte A, Sejnowski TJ, Behrens MM. How Nox2-containing NADPH oxidase affects cortical circuits in the NMDA receptor antagonist model of schizophrenia. Antioxid Redox Signal 2013;18:1444-1462.

108. Hardingham GE, Do KQ. Linking early-life NMDAR hypofunction and oxidative stress in schizophrenia pathogenesis. Nat Rev Neurosci 2016;17:125-134.

109. Goussakov I, Miller MB, Stutzmann GE. NMDA-mediated $\mathrm{Ca}^{2+}$ influx drives aberrant ryanodine receptor activation in dendrites of young Alzheimer's disease mice. I Neurosci 2010;30:12128-12137.

110. Lane HY, Lin CH, Green MF, Hellemann G, Huang CC, Chen PW, et al. Add-on treatment of benzoate for schizophrenia: a randomized, double-blind, placebo-controlled trial of D-amino acid oxidase inhibitor. JAMA Psychiatry 2013;70:1267-1275.

111. Tsai GE, Falk WE, Gunther J, Coyle JT. Improved cognition in Alzheimer's disease with short-term D-cycloserine treatment. Am J Psychiatry 1999; 156:467-469.

112. Schwartz BL, Hashtroudi S, Herting RL, Schwartz P, Deutsch
SI. d-Cycloserine enhances implicit memory in Alzheimer patients. Neurology 1996;46:420-424.

113. Randolph C, Roberts JW, Tierney MC, Bravi D, Mouradian MM, Chase TN. D-cycloserine treatment of Alzheimer disease. Alzheimer Dis Assoc Disord 1994;8:198-205.

114. Tsai GE, Falk WE, Gunther J. A preliminary study of D-cycloserine treatment in Alzheimer's disease. J Neuropsychiatry Clin Neurosci 1998;10:224-226.

115. Chang $\mathrm{CH}$, Lane HY, Tseng PT, Chen SJ, Liu CY, Lin CH. Effect of $\mathrm{N}$-methyl-D-aspartate-receptor-enhancing agents on cognition in patients with schizophrenia: a systematic review and meta-analysis of double-blind randomised controlled trials. J Psychopharmacol 2019;33:436-448.

116. Yao L, Zhou Q. Enhancing NMDA receptor function: recent progress on allosteric modulators. Neural Plast 2017;2017: 2875904.

117. Hashimoto K, Fukushima T, Shimizu E, Okada S, Komatsu N, Okamura N, et al. Possible role of D-serine in the pathophysiology of Alzheimer's disease. Prog Neuropsychopharmacol Biol Psychiatry 2004;28:385-388.

118. Biemans EA, Verhoeven-Duif NM, Gerrits J, Claassen JA, Kuiperij HB, Verbeek MM. CSF D-serine concentrations are similar in Alzheimer's disease, other dementias, and elderly controls. Neurobiol Aging 2016:42:213-216.

119. Madeira C, Lourenco MV, Vargas-Lopes C, Suemoto CK, Brandão CO, Reis T, et al. D-serine levels in Alzheimer's disease: implications for novel biomarker development. Trans/ Psychiatry 2015;5:e561.

120. Nuzzo T, Miroballo M, Casamassa A, Mancini A, Gaetani L, Nisticò R, et al. Cerebrospinal fluid and serum d-serine concentrations are unaltered across the whole clinical spectrum of Alzheimer's disease. Biochim Biophys Acta Proteins Proteom 2020;1868:140537.

121. Lin $\mathrm{CH}$, Lane HY, Tsai GE. Glutamate signaling in the pathophysiology and therapy of schizophrenia. Pharmacol Biochem Behav 2012;100:665-677.

122. Lin $\mathrm{CH}$, Lane HY. Early identification and intervention of schizophrenia: insight from hypotheses of g/utamate dysfunction and oxidative stress. Front Psychiatry 2019;10:93.

123. Van den Berghe-Snorek S, Stankovich MT. Thermodynamic control of D-amino acid oxidase by benzoate binding. J Biol Chem 1985;260:3373-3379.

124. Lin CH, Chen PK, Chang YC, Chuo LJ, Chen YS, Tsai GE, et al. Benzoate, a D-amino acid oxidase inhibitor, for the treatment of early-phase Alzheimer disease: a randomized, double-blind, placebo-controlled trial. Biol Psychiatry 2014;75: 678-685. 